
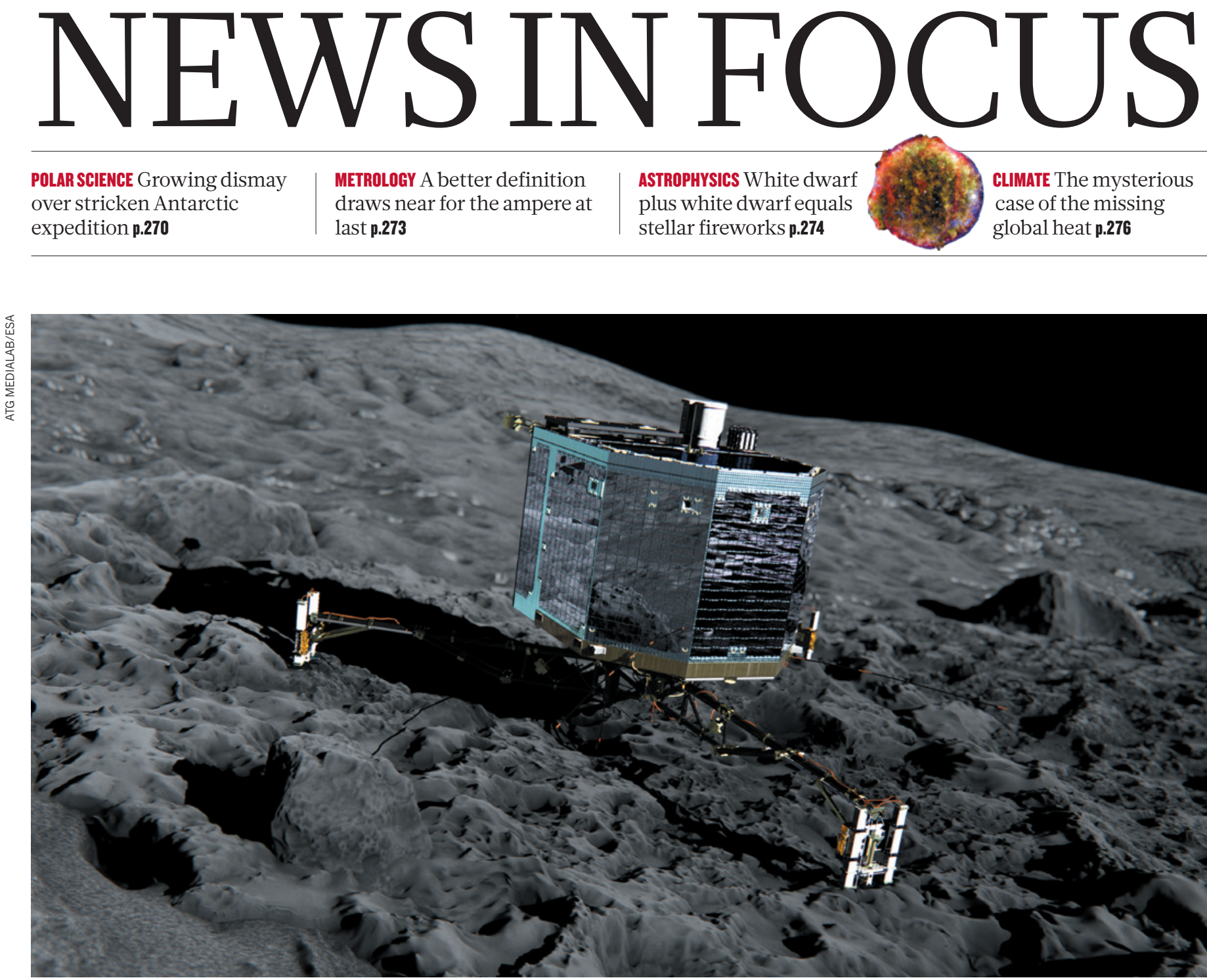

In November 2014, the Philae lander will be the first to try to land on the surface of a comet, 67P/Churyumov-Gerasimenko, as shown in this artist's impression.

\title{
Comet craft ready to wake
}

\section{Stakes high as European Space Agency waits for Rosetta orbiter to come out of hibernation.}

\section{BY ELIZABETH GIBNEY}

S pace scientists are used to moments of high tension. They often have just one chance to get things right, and experiments can hinge on the success of equipment that may be millions of kilometres away. So there will be considerable anxiety on 20 January at the European Space Agency (ESA) when the comet-hunting spacecraft Rosetta is due to stir after almost three years of hibernation.

With Rosetta now some 800 million kilometres from Earth, and rapidly approaching its target - comet 67P/Churyumov-Gerasimenko - the first sign that things are going to plan on Rosetta will be the activation of a pre-set alarm.
This will trigger a series of automated events that should see the craft's components warmed up, its spin corrected with thrusters and an antenna pointed at Earth to begin communications. There will be an anxious wait.

"I can tell you, you sweat like hell," says Claudio Sollazzo, operations manager of ESA's 2005 Huygens mission to Saturn's moon Titan, who endured about two weeks of radio silence after the probe was released from the Cassini orbiter. "With every second of delay, immediately you say, 'OK - something has gone wrong.' You can know you've done everything right, but it's always human nature to believe something bad has happened."

Once Rosetta is awake, the stakes will get higher. Later this year, mission controllers will attempt to observe the comet up close and land the craft's probe, Philae - the first time a comet landing has been attempted. Both objectives aim to deliver vital data about the formation of the Solar System and life on our planet.

The $€ 1$-billion (US\$1.4-billion) mission has been hurtling through the Solar System since 2004. Its 7-billion-kilometre journey has seen it fly past asteroids, and slingshot around Earth and Mars before it was put into hibernation to save energy in June 2011.

Rosetta will arrive at its target in August, when it will map the comet's surface, gravity, shape and rotation to find a suitable site to dispatch the metre-cubed Philae lander (see 


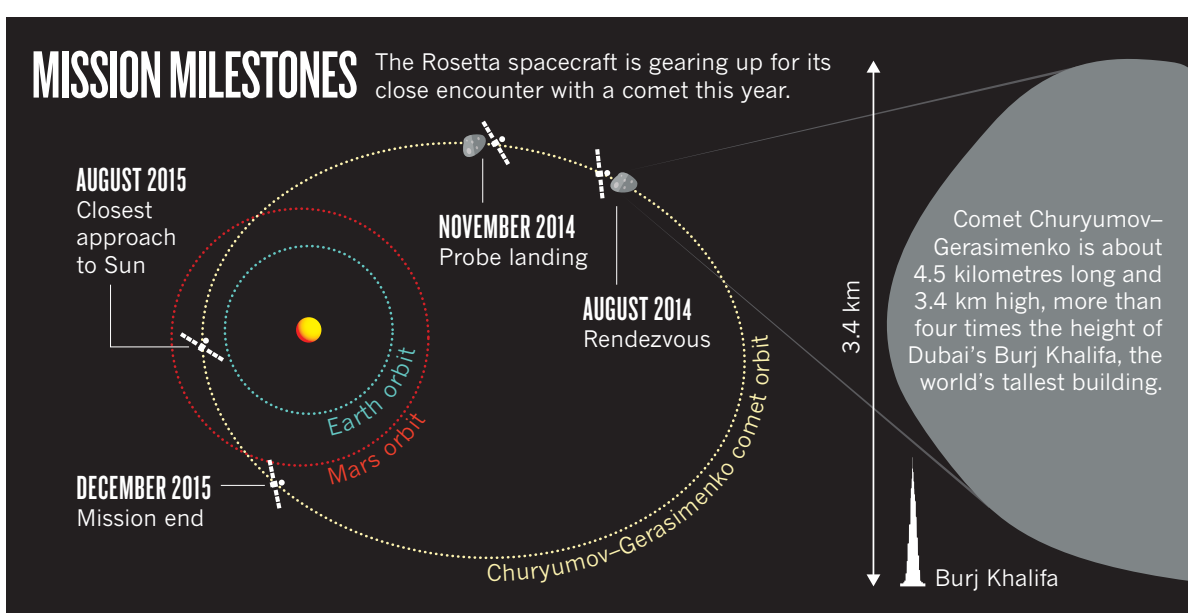

> 'Mission milestones'). "We really know very little about this object," says Andrea Accomazzo, Rosetta's spacecraft-operations manager.

ESA plans to release Philae in November, before the comet - already spewing gas and dust - gets too close to the Sun, when it will start to produce more debris. Rosetta, which will ordinarily orbit at up to 100 kilometres from the comet, will descend to about 4 kilometres away for the landing, and will drop its instrument-laden probe unpowered into a zone about one kilometre squared. With just one shot at the landing, which will be automated because of a 30-minute delay in communications with Earth, the operation will be risky. "Even though we will have chosen the best possible site, we'll still need some luck to land on a safe part," says Mark McCaughrean, senior scientific adviser at the ESA directorate of science and robotic exploration. Rosetta will circle the comet at the equivalent of walking pace, albeit as both hurtle along at 20 kilometres per second.

Once Philae has secured itself on the surface using a harpoon, its batteries will last a few days; after this it must survive on solar power, which will be difficult once its panels are covered in dust. "We really don't know how long it will last," says McCaughrean. Although the emphasis will be on the lander's performance, just getting the orbiting spacecraft and its complex instruments into position around the comet will be a big success, he says. "If we put the lander on the surface, that's the cherry on the cake."

Comets are primitive objects. Their gas, dust and organic molecules have changed little since their creation along with the Solar
System 4.6 billion years ago. Scientists think that they hold strong clues about its origins. Comets are also thought to have delivered a large fraction of Earth's water, and possibly amino acids, the building blocks of life.

Assuming all goes to plan, cameras and sensors on the orbiter will examine the comet in detail over the next year, while spectrometers analyse the chemistry of its dust. The lander will look at the comet's surface composition and structure. Both will assess the ratio of normal to heavy water - formed from the hydrogen isotope deuterium - to see if comet ice matches Earth's water signature, and their instruments will hunt for the complex organic molecules that are needed to assemble primitive life.

Uwe Meierhenrich, an analytical chemist at the University of Nice Sophia Antipolis in France, will be anxiously waiting for the results. He is co-investigator of Philae's COSAC (Cometary Sampling and Composition) experiment, which will analyse materials from around 20 centimetres beneath the comet's surface. These might include organic materials that do not vaporize and never form part of the gas tail that astronomers can study from Earth.

COSAC will also measure the chirality (or 'handedness') of any detected amino acids, something that is impossible through remote observation and has never been done before on comet samples, says Meierhenrich. On Earth, amino acids in proteins are left-handed, so finding a predominance of left-handed molecules on the comet would add weight to theories that such a cosmic traveller seeded life on Earth by providing essential basic ingredients.

\section{Researchers question rescued polar expedition}

\section{Australian Antarctic Division says it did not approve research strategy of stricken mission.}

\section{BY ALEXANDRA WITZE}

$\mathrm{T}$ he Australian Antarctic Division (AAD) has added its voice to the growing criticism of a stricken private polar expedition by challenging claims that it approved the research element of the trip.

On page 291 of this issue, Nick Gales, chief scientist of the AAD, which is based in Kingston, Tasmania, responds to an earlier Nature column by expedition head Chris Turney of the University of New South Wales (see Nature 505, 133; 2014). Turney's Australasian Antarctic Expedition aimed to retrace the steps of explorer Douglas Mawson, who led an outing a century ago. But members of Turney's expedition had to be rescued from their ship, the $M V$ Akademik Shokalskiy, after it became trapped in ice at Christmas, adding fuel to a debate about the merits of such privately funded trips.

Gales challenges Turney's implicit suggestion that the AAD had approved the expedition's science plan. The AAD did not formally review the research strategy, Gales notes, but had issued the permits required for Turney's group to visit the region in which it got stuck. "It's an important distinction for us," says Gales. He adds that the expedition's rescue has delayed several projects in Australia's national Antarctic programme that have been many years in the planning.

Other polar scientists have criticized the ninepoint science plan laid out on the expedition's website. The plan "could be interpreted as delivering outcomes that I believe are not possible from this single voyage", says Richard Coleman, deputy director of the Institute for Marine and Antarctic Studies at the University of Tasmania in Hobart, Australia. For instance, the plan's first bullet point says that the expedition aims to "gain new insights into the circulation of the Southern Ocean and its impact on the global carbon cycle". A single trip could provide only 